\title{
ELEVAÇÃO DAS MÉDIAS PRETÔNICAS POR HARMONIA: QUESTÕES TEÓRICAS E EMPÍRICAS
}

\author{
RISING OF MID UNSTRESSED VOWELS THROUGH HARMONY: \\ THEORETICAL AND EMPIRICAL ISSUES
}

\author{
Gisela Collischonn \\ Professora da Universidade Federal do Rio Grande do Sul/CNPq \\ giselac@via-rs.net \\ Márcia Eliane da Silva \\ Doutoranda do Curso de Pós-Graduação \\ Letras da Universidade Federal do Rio Grande do Sul \\ marciaelian@ig.com.br
}

\begin{abstract}
RESUMO: O fenômeno da harmonia vocálica das vogais médias pretônicas no português brasileiro é retomado à luz de duas sínteses teóricas publicadas em anos recentes a respeito das características tipológicas e dos condicionamentos do fenômeno da harmonia vocálica nas línguas (HULST e van der WEIJER, 1995; ARCHANGELI; PULLEYBLANK, 2007). Procuramos discutir alguns aspectos da harmonia em português, confrontando-os com as perspectivas teóricas apresentadas nos dois textos analisados. Para tanto, trazemos um breve panorama das características da harmonia da pretônica, a partir de estudos sistemáticos, principalmente de cunho variacionista, realizados em diferentes variedades do português brasileiro. Essa análise não tem o propósito de ser exaustiva, mas de permitir uma contextualização dos aspectos que serão tratados na discussão subsequente. Apresentamos as questões fundamentais que nortearam a caracterização da harmonia em Hulst e van der Weijer (1995). Questões como a natureza dos traços envolvidos e o problema da localidade são levantadas e discutidas com relação ao fenômeno no português brasileiro. Apresentamos também a caracterização da harmonia na perspectiva de Archangeli e Pulleyblank (2007) e indicamos a mudança de perspectiva evidenciada neste estudo em relação ao anterior. Algumas das questões que esses estudos teóricos levantam já foram amplamente discutidas com relação aos dados do português. Outras, entretanto, ainda não mereceram investigação empírica aprofundada. A discussão que empreendemos no artigo aponta para essas questões e identifica também alguns problemas que as teorias ainda não conseguiram resolver.
\end{abstract}

PALAVRAS-CHAVE: Harmonia vocálica; Português brasileiro; Variação fonológica.

ABSTRACT: The phenomenon of vowel harmony of the unstressed mid vowels in Brazilian Portuguese is taken up in the light of two theoretical syntheses published in recent years about the typological characteristics and constraints of the phenomenon of vowel harmony (van der HULST; WEIJER, 1995; ARCHANGELI; PULLEYBLANK, 2007). Our aim is to discuss some aspects of harmony in Portuguese, confronting them with the theoretical perspectives presented in the two texts analyzed. To this end, we present a brief overview of the characteristics of unstressed vowel harmony from systematic studies, especially variationist studies carried out in different varieties of Brazilian Portuguese. This analysis is not intended to be exhaustive, but to allow the contextualization of aspects that will be addressed in the subsequent discussion. We present the fundamental questions that guided the characterization of harmony in van der Hulst and Weijer (1995). Issues such as the nature of the features involved and the 
problem of locality are raised and discussed with respect to the phenomenon in Brazilian Portuguese. We also present a characterization of harmony according to Archangeli and Pulleyblank (2007) and indicate the change in perspective evidenced in this study compared to the previous. Some of these theoretical issues raised have already been widely discussed in relation to data from Portuguese. Others, however, have not yet received thorough empirical investigation. The discussion we undertake in this article points to these questions and also identifies some problems that theories have failed to solve.

KEYWORDS: Vowel harmony; Brazilian Portuguese; Phonological variation.

\section{INTRODUÇÃO}

O presente artigo retoma o fenômeno da harmonia vocálica da pretônica no português brasileiro, à luz de duas sínteses teóricas publicadas em anos recentes a respeito das características tipológicas e dos condicionamentos do fenômeno da harmonia vocálica nas línguas naturais (HULST e van der WEIJER, 1995; ARCHANGELI; PULLEYBLANK, 2007). A seleção desses dois textos deu-se em função de que se trata de dois capítulos que figuram em destacadas publicações que buscam, cada uma a seu tempo, apresentar o "estado da arte" teórico/descritivo a respeito de determinados temas da fonologia. Procuramos discutir alguns aspectos da harmonia em português brasileiro, confrontando-os com as perspectivas teóricas apresentadas nos dois textos analisados.

O fenômeno da harmonia vocálica figura entre os mais estudados, no que se refere à fonologia do português. São duas as razões para isso: em primeiro lugar, o interesse que este tipo de fenômeno suscitou para a fonologia autossegmental e, em segundo lugar, o fato de que, especificamente no que se refere à harmonia vocálica da pretônica, se trata de um fenômeno variável, com condicionamento tanto de natureza social quanto linguística, e que, portanto, se presta à análise pela metodologia quantitativa desenvolvida por William Labov e colaboradores. Na fonologia autossegmental, traços são vistos como relativamente independentes dos segmentos que os possuem e suscetíveis de espraiamento para outros segmentos da sequência fonológica, por vezes, bastante afastados do segmento-fonte. Essa abordagem procura não somente explicar como fenômenos do tipo da harmonia são possíveis, mas também procura determinar as condições dentro das quais eles são possíveis, i.e. determinar os parâmetros ou princípios que atuam no sentido de restringir esse tipo de fenômeno.

É de se reconhecer que os estudos realizados ao longo das últimas três décadas permitem que tenhamos hoje muito mais informações a respeito do fenômeno da harmonia da pretônica no português do Brasil. No entanto, como pretendemos mostrar aqui, há ainda muitas questões empíricas não respondidas e vários problemas teóricos não abordados. Quanto à organização do artigo, na seção seguinte, trazemos um breve panorama das características da harmonia da pretônica, a partir de estudos sistemáticos, principalmente de cunho variacionista, realizados em diferentes variedades do português brasileiro. Essa análise não tem o propósito de ser exaustiva, mas de permitir uma contextualização dos aspectos que serão tratados nas seções subsequentes. Em seguida, apresentamos as questões fundamentais que nortearam a caracterização da harmonia em Hulst e van der Weijer (1995). Questões como a natureza dos traços envolvidos e o problema da localidade são levantadas e discutidas com relação ao fenômeno no português brasileiro. Na terceira seção, apresentamos a caracterização da harmonia na

Work. Pap. Linguíst., 13(2): 01-14, Florianópolis, abr/jul, 2013 
perspectiva de Archangeli e Pulleyblank (2007). A conclusão retoma, resumidamente, os temas aqui abordados.

\section{A HARMONIA DA PRETÔNICA NO PORTUGUÊS BRASILEIRO}

O fenômeno assimilatório da harmonia vocálica da pretônica caracteriza-se pela elevação das vogais médias /e/ e /o/ átonas pretônicas, quando precedem uma sílaba com vogal alta, seja /i/ ou /u/, como em bebida, ferida, cetim, feliz, apelido, soluço, fortuna etc. O fenômeno foi e está sendo estudado em diversas regiões do país (especialmente pelos pesquisadores associados ao Projeto PROBRAVO). Constata-se que a elevação das vogais médias pretônicas é claramente favorecida pelo contexto de uma vogal alta em sílaba subsequente (cf. BISOL, 1981), razão por que a elevação ficou conhecida como harmonia vocálica da pretônica.

No poema Mortal Loucura, de Gregório de Matos, encontramos um atestado escrito de que o fenômeno estava ativo na língua no século XVII. Neste poema há uma rima que é uma espécie de eco, e que retoma integralmente parte da última palavra do verso a qual constitui uma nova palavra, com sentido diferente, quase sempre contrário ao da palavra ecoada. No trecho abaixo, na penúltima linha, destacamos as formas que revelam a harmonia vocálica em form [u]sura.

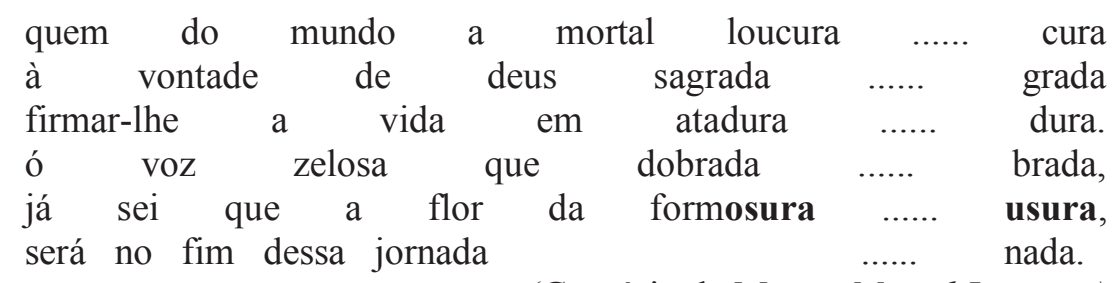

(Gregório de Matos, Mortal Loucura)

Poderíamos esperar que, ao longo dos quase quatro séculos que nos separam do tempo de Gregório de Matos, a mudança já teria se consolidado, na forma de uma reestruturação das formas subjacentes das palavras. No entanto, o que se observa é que ainda hoje a variação perdura. Em um levantamento com dados do Projeto NURC, Callou et al. (2009) constatam uma taxa de elevação da pretônica em torno de 30\% nas capitais estudadas.

Tabela 1 Taxas de input de harmonização vocálica por capital ${ }^{1}$ - Callou et al. (2009, p.135)

\begin{tabular}{|c|c|c|c|c|}
\hline Porto Alegre & São Paulo & Rio de Janeiro & Salvador & Recife \\
\hline 0,22 & 0,24 & 0,32 & 0,25 & 0,28 \\
\hline
\end{tabular}

Fonte: Callou et al. 2009, p.135.

Do norte ao sul do Brasil, as taxas de elevação da vogal no contexto pretônico estão em torno de 30\%: em Breves, no Pará, Cassique et al. (2009) observaram uma probabilidade de elevação de 0,33, e, em Cametá, Pará, Rodrigues e Araújo (2007)

\footnotetext{
${ }^{1}$ Conforme Tagliamonte (2006, p.141), “O 'Input', também conhecido como 'média corrigida', é uma medida global da taxa de aplicação da regra (GUY, 1988: 126) e pode ser entendido como uma 'indicação geral da força de uma regra' (YOUNG A; BAYLEY ,1996: 270) ou 'uma freqüência média de ocorrência do valor de aplicação da variável dependente' (PAOLILLO, 2002: 79)."

Work. Pap. Linguíst., 13(2): 01-14, Florianópolis, abr/jul, 2013
} 
observaram 0,29 para /e/ e 0,41 para /o/; no Rio Grande do Sul, Bisol (1981) observou uma porcentagem de elevação de 38\% para /e/ e 36\% para /o/; Schwindt (2002) chegou a resultados semelhantes: porcentagem de elevação de 36\% para /e/ e 42\% para /o/. Análises recentes de dados do noroeste do estado de São Paulo também têm encontrado valores semelhantes; Tenani e Silveira (2008) relatam pesquisa feita com 16 informantes da região de São José do Rio Preto, na qual encontraram porcentagens de elevação de 39\% para /e/ e 41\% para /o/, quando em contexto precedente à vogal alta /i/. Silva (2012) fez uma análise da fala de São José do Norte, no Rio Grande do Sul, a partir dos dados coletados para o estudo de Amaral (2000), e encontrou aplicação de $41 \%$ para /e/ e $43 \%$ para $/ 0 / .^{2}$

Callou et al. (2009) também observam que existe uma diferença entre o condicionamento exercido pela vogal /i/ em relação a /u/. Segundo os autores, em geral, é mais provável que a vogal $/ \mathrm{i} /$ desencadeie o processo do que a vogal $/ \mathrm{u} / .^{3} \mathrm{Com}$ os dados do Projeto NURC, foi constatada uma diferença significativa na aplicação da harmonia, com peso relativo de 0,78 para /i/, comparado ao de 0,31 para /u/. Ou seja, é mais provável a elevação em perigo e sovina do que em peruca e soluço.

Ao que parece, a harmonia da pretônica não está avançando nem diminuindo, é um fenômeno de variação estável. No português europeu, houve um processo de elevação que avançou muito mais, de modo que, atualmente, as vogais médias pretônicas são realizadas quase sempre como [i] (uma vogal alta central) e [u] (ex. [si'lar] para selar, [fur'sar] para forçar), ou então são apagadas (ex. [s'lar] para selar). Segundo Révah (1958) apud CALLOU; LEITE; MORAES (2002, p.11), considerando que a elevação da vogal pretônica já teria estado praticamente consolidada no português europeu no século XV - período da colonização - a variação atualmente existente no Brasil seria uma restauração. Os autores, porém, entendem que a variação no português brasileiro seja uma pronúncia conservadora, indicando evidências de que o português trazido pelos colonizadores não tinha consolidado ainda a elevação das vogais pretônicas.

Há alguns processos que interagem com a harmonia vocálica. Leite e Callou (2002) observam que "Para o português do Brasil, as vogais pretônicas, grafadas $e$ e $o$, estabelecem a linha divisória entre os falares do Norte, que optam pela realização aberta, e os falares do Sul, que optam pela realização fechada" (p.39-40). Os dados do NURC indicam percentuais altos de vogais [3] e [0] pretônicas em Salvador (60\%) e em Recife (47\%) comparados aos do Rio de Janeiro (5\%) e de São Paulo e Porto Alegre $(0 \%)$. Alguns exemplos de realização de vogal média baixa na pretônica, de acordo com Hora (2005) são: ch[3]fão, entr[3]vado, c[o]lapso, c[0]rreto. A realização aberta pode ser motivada, em parte, por um processo de harmonia das vogais abertas, pois, ao que tudo indica, a vogal /a/ participa como gatilho do processo (HORA, 2005; LEE; OLIVEIRA, 2003). Entretanto, nem todas as formas podem ser explicadas por esse processo harmônico adicional. Hora (2005) cita também formas como ab[3]rtura e c[0]1[e]ção, nas quais, a motivação harmônica não existe.

\footnotetext{
${ }^{2}$ Há muitas outras análises representativas do fenômeno variável; cf. Cardoso (1999).

${ }^{3}$ Cabe observar que a harmonia não é provocada por uma vogal alta realizada como glide, esteja ela presente na mesma sílaba que a vogal alvo, faceirice, doidice, esteja em sílaba subsequente, pereirra, pereiral, roceira, roceírada; ou seja, a vogal-fonte tem de ser núcleo de sílaba para que ocorra o processo. Além disso, a vogal-alvo também não pode ser ladeada por uma semivogal, por exemplo, em leitura, feitio, mineirice, direitista não há aplicação, o que cremos ser sistemático.
}

Work. Pap. Linguíst., 13(2): 01-14, Florianópolis, abr/jul, 2013 
Considerando-se que as taxas de elevação por harmonia encontradas em Salvador e Recife nos dados do Projeto NURC são bastante semelhantes às de outras capitais, parece que o fenômeno de abaixamento não interfere no processo de elevação. No entanto, dados como os abaixo mostram que também há alternância entre elevação e abaixamento da vogal (cf. HORA, 2005):
a) $\quad$ al $[\varepsilon]$ gria $\sim \operatorname{al}[i]$ gria
b) $\quad \mathrm{c}[$ o]ruja $\sim \mathrm{c}[\mathrm{u}] \mathrm{ruja}$
$\mathrm{b}[\varepsilon]$ bida $\sim \mathrm{b}[\mathrm{i}]$ bida
$\mathrm{c}[$ o]stura $\sim \mathrm{c}[\mathrm{u}]$ stura
$\mathrm{m}[\varepsilon]$ dida $\sim \mathrm{m}[\mathrm{i}]$ dida
$\operatorname{desc}[$ o]berta $\sim \operatorname{desc}[\mathrm{u}]$ berta
$\mathrm{p}[\varepsilon]$ dido $\sim \mathrm{p}[\mathrm{i}]$ dido
$\operatorname{pr}[\varepsilon]$ guiça $\sim \operatorname{pr}[\mathrm{i}]$ guiça

Segundo Lee e Oliveira (2003), no dialeto mineiro, as formas sujeitas à elevação não apresentam abaixamento e vice-versa. Há, portanto, necessidade de maior quantidade de estudos sistemáticos sobre o abaixamento das vogais nos falares das regiões Norte, Nordeste, e também no Centro-Oeste, para que se possa compreender a natureza da interação entre os dois processos. Outros processos de elevação interagem com a harmonia vocálica, como constata Bisol $(1981,1988)$ : provocam a elevação de /o/ as consoantes precedentes labiais: /p, b, f, v, m/ (b[u]nita) e dorsais /k, g/ (c[u]lina); provocam a elevação de /e/, quando esta vogal estiver em início de palavra, as consoantes seguintes [s, z] ([i]scola, [i]xame) e a consoante nasal ([i]nsino). Há evidência de que esse último processo seja distinto da harmonia vocálica, pois a vogal nasal só é elevada no início de palavra, em outras posições, a nasalidade da vogal bloqueia ou restringe a elevação (BISOL, 1981; SCHWINDT, 1995). ${ }^{4}$ Também com relação à influência da consoante precedente, conforme Schwindt (2002, p. 175), parece tratar-se de outra regra que atua combinada à harmonia, em formas como cozinha, buzina, mas que também pode atuar sozinha, como em $b[\mathrm{u}]$ neca, $b[\mathrm{u}]$ lacha, $c[\mathrm{u}]$ lher, $c[\mathrm{u}]$ mpadre etc.

Como vimos, o processo de elevação de vogal média pretônica caracteriza-se como processo de harmonia de realização variável, sem indícios de mudança em curso ou, se houver avanço, este parece ser bastante lento. Há outros casos de elevação de vogais médias pretônicas, próximos do categórico, mas que não se caracterizam como harmonia vocálica, por se aplicarem independentemente da existência de vogal alta na palavra.

\section{A CARACTERIZAÇÃO DA HARMONIA VOCÁLICA: HULST E VAN DER WEIJER (1995)}

No quadro da fonologia autossegmental e da geometria de traços, Hulst e van der Weijer (1995) preocupam-se principalmente em estabelecer uma tipologia da harmonia e apontam para questões que uma teoria abrangente da harmonia vocálica deveria explicar, a saber, o domínio, a natureza dos traços envolvidos no processo e a

\footnotetext{
${ }^{4}$ Schwindt (2001) nota que a elevação também se dá quando a vogal média é precedida por um prefixo: re[i]xaminar, re[i]ncaminhar. Essa observação aponta para uma tendência de realização categórica com vogal alta de sequências desse tipo $e N$, $e z$, estejam elas em início absoluto, estejam em início de palavra prosódica interna a outra palavra prosódica (sobre a recursividade dessas estruturas, ver a seção 2).

Work. Pap. Linguíst., 13(2): 01-14, Florianópolis, abr/jul, 2013
} 
localidade, isto é, a condição de adjacência entre os segmentos envolvidos. Embora muitas das questões que os autores levantam estejam relacionadas a questões específicas da teoria autossegmental de traços - teoria que deixou de estar no foco principal das atenções em anos recentes - diversas questões continuam relevantes para a teorização da fonológica atual.

Com relação ao domínio, os autores reconhecem que é a palavra prosódica que é, em geral, identificada como o domínio da harmonia. Em parte, essa análise se deve ao fato de que, via de regra, a harmonia não atravessa fronteiras entre membros de palavras compostas. Por exemplo, no português, num composto, como odonto-clínica, velocímetro ou ferrovia, não ocorre a elevação da vogal do primeiro membro do composto. No entanto, a tese de que são domínios prosódicos - e não morfológicos - os que condicionam processos autossegmentais não foi suficientemente testada empiricamente. Segundo os autores, na maior parte dos casos que reanalisaram, não haveria evidência empírica suficiente a favor de um domínio prosódico e não meramente morfológico. ${ }^{5}$ Cabe apontar para a necessidade de mais levantamentos nessa área, especialmente no que se refere ao comportamento da harmonia na fronteira entre constituintes morfológicos. Considerando-se que a harmonia vocálica seja um fenômeno de natureza pós-lexical, eventuais condicionamentos que pareçam de caráter morfológico devem ser analisados mais a fundo.

Com relação à natureza dos traços, a questão principal que Hulst e van der Weijer (1995) buscam responder é como acomodar os diversos sistemas de harmonia das línguas do mundo em uma teoria universal da natureza e da organização dos traços distintivos. A harmonia é vista como preenchimento de traços em um segmento que carece de determinado traço. O preenchimento se dá através de compartilhamento de um traço, estabelecendo-se uma associação dupla, envolvendo o segmento possuidor do traço e o segmento carente. A carência de traços explica-se pela teoria da subespecificação ou pela teoria dos traços monovalentes. No primeiro caso, a subespecificação é temporária, ou seja, num intervalo derivacional, um segmento não possui especificação, recebendo mais tarde a inserção do traço, por regra geral (ARCHANGELI, 1988). Na segunda perspectiva, universalmente, somente há um valor para um determinado traço - por exemplo, somente há o valor [+arredondado] - e somente este valor pode se espraiar (ou seja, pode associar-se a mais de um segmento).

No que se refere à harmonia do português, embora diversos trabalhos tenham uma concepção geométrica da harmonia (por exemplo, SCHWINDT, 2002; ABAURRE; SÂNDALO, 2009, entre outros), apenas em Matzenauer e Miranda (2003, p.107) encontramos uma representação em termos autossegmentais do processo. Por conseguinte, há também uma ausência quase total da discussão a respeito da especificação ou não-especificação dos segmentos, alvo e gatilho, quanto aos traços envolvidos. A segunda questão a que Hulst e van der Weijer se dedicam refere-se à caracterização dos traços envolvidos nos processos de harmonia vocálica. Esta questão é claramente dependente da perspectiva adotada com relação aos traços, se binários ou monovalentes. Para processos de harmonia que envolvem altura ou posição da raiz da língua (abertura/fechamento), como é o caso da harmonia em português, existe

${ }^{5}$ Em outro trabalho, Collischonn (2013) desenvolveu a análise desta questão, voltada para os dados do português brasileiro.

Work. Pap. Linguíst., 13(2): 01-14, Florianópolis, abr/jul, 2013 
dificuldade em determinar se o processo envolve altura ou posição da raiz da língua, pois as dimensões não são plenamente independentes.

Esse problema tem pautado alguma discussão a respeito do português. Com relação ao processo de elevação, ele tem sido consistentemente tratado como envolvendo uma dimensão de altura (representada pelo traço [+alto] ou por um traço escalar de abertura, conforme a geometria de Clements e Hume, 1995). ${ }^{6}$ Por outro lado, o abaixamento da pretônica, em formas como c[0]rreto, inicialmente interpretado como referindo-se ao traço [+baixo], passou a ser analisado como harmonia de [ATR] em Lee e Oliveira (2003). Para Wetzels (1992), os diversos fenômenos de neutralização e de harmonia vocálica caracterizam mudança em uma única dimensão: a abertura da cavidade oral, caracterizada através do traço binário [aberto], que se desdobra em vários graus de abertura (CLEMENTS; HUME, 1995). Outros defendem que os fenômenos sejam mais bem caracterizados através de um conjunto de traços de altura combinado com um traço referente à posição da raiz da língua [ATR] (Advanced Tongue Root), traço utilizado para a caracterização da harmonia nas línguas banto. ${ }^{7}$ A questão é diretamente relacionada ao tema dos universais em termos de constituição de traços, razão por que consideramos importante destacá-la aqui.

No que se refere à localidade, há também a questão de como interpretar a inércia dos segmentos intervenientes. Como explicar que um traço passou de uma vogal para outra se há uma (ou até mais de uma) consoante no meio? O problema da localidade se delineia especialmente a partir do momento em que, no âmbito da fonologia autossegmental, os processos assimilatórios passam a ser considerados como instâncias de compartilhamento de traços. Hulst e van der Weijer citam Steriade (1995), que diz que associações não-locais sempre devem ser consideradas com suspeição. Essa perspectiva encontra expressão, na fonologia autossegmental, no princípio de nãocruzamento de linhas de associação (ver MATZENAUER, 2005, p.64-65).

A questão do papel das consoantes intervenientes com relação à harmonia do português ainda não mereceu uma análise acurada, na perspectiva da representação autossegmental. O que temos são levantamentos de tipos de consoantes posteriores à vogal-alvo que condicionam a elevação (ver, por exemplo, BISOL, 1988). Sabemos também que uma vogal-alvo em sílaba travada por consoante tende a não se elevar. Essa última observação poderia ser explicada com base em um bloqueio da harmonia quando entre vogal-alvo e vogal-gatilho se encontram duas consoantes. Quanto ao papel condicionador de consoantes individuais, os resultados dos estudos não permitem concluir que determinadas consoantes travem o processo de harmonia.

\footnotetext{
${ }^{6}$ Matzenauer e Miranda (2003) representam o processo como desligamento do nó Abertura da vogal média e espraiamento do nó Abertura da vogal-gatilho, mas o processo pode ser entendido também como desligamento de [+aberto2] apenas, seguido de ligamento de [-aberto2].

${ }^{7}$ Calabrese (1985) adota o traço [ATR] para a análise da metafonia em Salentino e diversos escritos do autor defendem a adoção do traço ATR para caracterizar os processos que afetam as vogais médias nas línguas românicas. Entretanto, Ladefoged e Maddieson (1996) argumentam contrariamente ao emprego desse traço nas línguas românicas. Wetzels (2010) apresenta argumentos contrários ao emprego do traço no português. Matzenauer e Miranda (2009) defendem o emprego de [ATR] em comparação com [RTR] (Retracted Tongue Root) proposto por Fikkert (2005) para a análise do português europeu. Nevins (2007, n.3) considera que a distinção entre as vogais médias em português seja entre vogais tensas e relaxadas, o que justificaria o emprego de [ATR].

Work. Pap. Linguíst., 13(2): 01-14, Florianópolis, abr/jul, 2013
} 
Outro problema relacionado à localidade refere-se à transparência/opacidade das vogais intervenientes. No caso da harmonia da pretônica, uma vogal baixa que intervém entre alvo e gatilho, por exemplo, em negativo, desfavorece o processo de harmonia de tal forma que podemos pensar em bloqueio da regra. Em termos de representação geométrica, bloqueios desse tipo são explicados com base na proibição de cruzamento de linhas de associação. Neste caso, a vogal baixa /a/ não seria alvo do processo e impediria a passagem do traço para o segmento vocálico à sua esquerda. Entretanto, para que a proibição de cruzamento de linhas possa ser interpretada, /a/ tem de estar associado ao traço [-alto], impedindo a passagem da linha de associação do traço para o segmento vocálico à sua direita. O problema é que /a/ é redundantemente [-alto], portanto, não se esperaria que fosse especificado para este traço. Problema parecido surge com relação ao processo de abaixamento: como explicar que /a/ participa do processo se não for especificado para o traço envolvido? Com base em estudo experimental com informantes de Minas Gerais, Espírito Santo e Goiás, Abaurre e Sândalo (2009) defendem que /a/ não participa do processo de abaixamento por ser plenamente não-especificado. Nessa análise, o abaixamento envolve o traço [+aberto], para o qual unicamente as vogais médias baixas tônicas seriam especificadas, o que explicaria a inércia de /a/. Entretanto, dados de outros dialetos (HORA, 2005) mostram que /a/ também desencadeia o abaixamento, o que implica a sua especificação como [+aberto]. Além disso, a análise de Abaurre e Sandalo (2009) não permitiria explicar o bloqueio da harmonia em negativo como instância da proibição de cruzamento de linhas. ${ }^{8}$

Como vemos, o papel exercido por vogais intervenientes está diretamente relacionado à nossa concepção a respeito de quais traços constituem a representação desses segmentos e, também, quais estão especificados, isto é, presentes, na representação dos segmentos e quais não estão. Até o momento, não temos uma análise que abarque essas questões para o português. Como veremos a seguir, o problema da opacidade recebe uma interpretação bastante diferente na abordagem da harmonia apresentada em Archangeli e Pulleyblank (2007).

\section{A HARMONIA VOCÁlICA DO PORTUGUÊS NO CONTEXTO UNIVERSAL: ARCHANGELI E PULLEYBLANK (2007)}

A análise panorâmica da harmonia vocálica em Archangeli e Pulleyblank (2007) é bastante diferente da de Hulst e van der Weijer (1995) e, de certa forma, reflete as mudanças por que passou a teoria fonológica nos 12 anos que separam uma publicação da outra. Se as questões de representação do processo assimilatório em termos de traços são fundamentais em Hulst e van der Weijer (1995), elas se tornam secundárias em Archangeli e Pulleyblank (2007). Os autores consideram que não há um status especial a ser atribuído à harmonia vocálica, dentre os demais tipos de processos assimilatórios. Para os autores, a harmonia é uma constelação particular de propriedades que ocorrem isoladamente em outros tipos de padrões fonológicos (ARCHANGELI; PULLEYBLANK, 2007 p. 353).

\footnotetext{
${ }^{8}$ Um problema semelhante surgiria com a especificação [-ATR] em vez de [+aberto]. Dado que /a/ é redundantemente [-ATR], não deveria participar do processo de abaixamento da pretônica.

Work. Pap. Linguíst., 13(2): 01-14, Florianópolis, abr/jul, 2013
} 
Segundo Cho (1990), qualquer processo assimilatório pode ser caracterizado pela especificação de um pequeno número de propriedades, dentro de um esquema universal:

1. local do espraiamento (i.e., se envolve um traço apenas ou um nódulo de classe);

2. especificação de alvo e/ou gatilho;

3. localidade (natureza da adjacência estrutural entre gatilho e alvo);

4. ordem relativa entre espraiamento e especificação de traço (considerando-se representações subespecificadas e atribuição default de traço);

5. direcionalidade do espraiamento;

6. domínio do espraiamento

Para Archangeli e Pulleyblank (2007), o padrão canônico da harmonia pode ser representado como $\left[V_{F} \ldots V_{F} \ldots V_{F} \ldots V_{F}\right]$, onde os colchetes indicam fronteiras de um determinado domínio e o índice ' $\mathrm{F}$ ' representa determinado traço. Portanto, no padrão canônico, todas as vogais em um determinado domínio possuem o mesmo traço (note-se que o compartilhamento de traços não é representado autossegmentalmente aqui). $\mathrm{Na}$ maioria dos casos, o sistema canônico não se realiza plenamente e o que explica esses desvios do padrão geral são limitações que se referem a condições sobre o segmento gatilho ou sobre o alvo, sobre a direção, a localidade e a possibilidade ou não de iteração. A síntese de Archangeli e Pulleyblank (2007) procura mostrar que qualquer processo de harmonia é caracterizado dentro do limite estabelecido pelas propriedades (variáveis) definidas por esse conjunto de condições. Essas propriedades variáveis poderiam ser interpretadas como parâmetros, de acordo com a teoria de Cho (1990), mas, como são consideradas limitadoras do processo geral da harmonia, também se prestam à interpretação em termos de restrições. Vale dizer que o capítulo está inserido em um livro em que a maioria dos capítulos trata da Teoria da Otimalidade. Ainda que os autores busquem mostrarem-se neutros teoricamente, sem apresentar uma análise através de restrições, não obstante, sua compreensão da harmonia como um processo geral, limitado por condicionadores, não deixa de refletir uma mudança na concepção teórica do processo da harmonia.

Condições sobre o segmento alvo podem ser referentes a traços ou a posições. No primeiro caso, uma vogal portadora de um determinado valor de traço pode ser alvo ao passo que as outras não podem. Da mesma forma, no que se refere ao gatilho, traços delimitadores dizem que um determinado segmento pode ser gatilho e outros não. No caso da harmonia da pretônica no português brasileiro, só são alvo as vogais [-bx]; então o traço [-bx] é delimitador do alvo. Além disso, a harmonia não parece ser desencadeada por glides, portanto, o gatilho tem de estar em posição de núcleo silábico. Essas limitações explicam o desvio em relação à situação idealizada na qual todas as vogais da sequência pretônica seriam uniformemente altas quando seguidas por um segmento vocálico especificado como [+alto]. ${ }^{9}$

Quanto ao domínio, sua natureza pode ser fonológica, morfológica ou sintática. Por exemplo, um domínio pode ser um pé ou uma palavra prosódica, mas também pode ser uma raiz, ou uma determinada combinação de raiz mais afixo. Portanto, Archangeli e Pulleyblank (2007) concordam com Hulst e van der Wijer (1995) em que o domínio não

\footnotetext{
${ }^{9}$ Além disso, é possível que tanto vogal-fonte quanto vogal-alvo sejam restritas às vogais anteriores (conforme LEITE; CALLOU; MORAES, 2003, p.12-13).
}

Work. Pap. Linguíst., 13(2): 01-14, Florianópolis, abr/jul, 2013 
precisa ser exclusivamente um constituinte prosódico (como a palavra fonológica). Por outro lado, por admitir uma ampla variedade de domínios de natureza diferente, sua abordagem não traz uma significativa contribuição no sentido de distinguir entre processos possíveis e aqueles que não seriam possíveis em termos de tipo de delimitadores. Como vimos anteriormente, a harmonia da pretônica em português parece ser limitada pela fronteira de uma palavra prosódica, e não por uma fronteira de caráter puramente morfológico. Adotando-se essa análise, mais restrita, do domínio da harmonia em português, tem-se um ponto de partida interessante para identificar comportamentos excepcionais, que, uma vez identificados, poderão receber mais investigação. Em geral, uma perspectiva mais abrangente é menos interessante do que uma mais restrita, porque não nos estimula a encontrar sub-padrões nos dados que analisamos.

Além das condições relativas ao gatilho ou ao alvo e ao domínio, a direção de aplicação da harmonia também pode variar. Em alguns casos, outros elementos condicionadores podem explicar essa direção, por exemplo, o traço harmonizado vai da raiz para os afixos (sufixos ou prefixos) ou da vogal tônica para a átona, i.e., essas condições posicionais a respeito do alvo ou do gatilho é que explicam a direção da harmonia. No entanto, segundo os autores, há casos em que a direcionalidade não se explica por esses outros fatores posicionais; portanto a teoria precisa permitir um mecanismo que explique a direcionalidade do processo. Na interpretação dos autores, a direcionalidade é expressa através de algum ponto de ancoragem em direção ao qual o processo de harmonia se realiza. Embora os autores não explicitem o conceito, ele parece estar relacionado a dois mecanismos formais propostos no âmbito da Teoria da Otimalidade: o de Alinhamento Generalizado (MCCARTHY; PRINCE, 2003) e o de Fidelidade Posicional (BECKMAN, 2003). No caso da harmonia pretônica no português, o processo parece envolver direcionalidade, da direita (isto é, da vogal-gatilho) para a esquerda (isto é, para as vogais pretônicas).

Finalmente, há casos em que harmonia acomoda-se ao segmento mais próximo e para, independentemente de direção e de posição de domínio. Isto significa que, além dos limitadores referentes ao alvo, ao gatilho ou ao domínio, as línguas ainda podem variar no que se refere à possibilidade de iteração ou não. De acordo com a representação canônica da harmonia, $\left[V_{F} \ldots V_{F} \ldots V_{F} \ldots V_{F}\right]$, a iteração parece ser compreendida como a aplicação default da harmonia, caso nenhum tipo de limitador interfira. Portanto, é a não-iteração que precisa de formalização explícita. No entanto, os autores não dão nenhuma indicação de como a não-iteração poderia ser formalizada.

Em português, como observa Bisol (1988), quando há mais de uma vogal média pretônica, o processo pode atingir todas as vogais, peregrino $\sim \mathrm{p}[\mathrm{i}] \mathrm{r}[\mathrm{i}]$ grino, mexerica $\sim$ $\mathrm{m}[\mathrm{i}] \mathrm{x}[\mathrm{i}] \mathrm{rica}$; ou então estaciona na vogal mais próxima ao gatilho, $\mathrm{p}[\mathrm{e}] \mathrm{r}[\mathrm{i}]$ grino, $\mathrm{m}[\mathrm{e}] \mathrm{x}[\mathrm{i}]$ rica. A explicação para a não-iteratividade, neste caso, é que o processo é variável, havendo portanto opcionalidade de aplicação iterativa ou não. Segundo Archangeli e Pulleyblank (2007), a teoria fonológica tem de dar conta da nãoiteratividade, pois, em não havendo impedimentos de localidade ou de outra natureza, a realização esperada seria aquela em que a harmonia se aplica no domínio todo. O que queremos dizer é que a análise do português, de acordo com a perspectiva apresentada em Archangeli e Pulleyblank (2007), necessitaria de um mecanismo formal para 
bloquear a aplicação iterativa para explicar formas como p[e]r[i]grino, $\mathrm{m}[\mathrm{e}] \mathrm{x}[\mathrm{i}]$ rica. Infelizmente, os autores não indicam os mecanismos disponíveis para isso. ${ }^{10}$

Em um processo harmônico iterativo, se um alvo potencial for encontrado que não pode harmonizar por não atender a determinada condição, então, em geral, a propagação da harmonia estaciona, caracterizando o efeito da opacidade. Já vimos o exemplo de negativo, em que a vogal baixa bloqueia a passagem do traço da vogal-gatilho para a vogal medida da sílaba inicial. Entretanto, em determinados processos de harmonia, parece que um segmento não se harmoniza mas também não limita o processo (i.e., a vogal é transparente). Chagas de Souza (2004) cita o exemplo do húngaro, Zsúzsi, Zsúzsival, respectivamente 'Suzi' e 'com a Suzi' nos quais a vogal /i/ não harmoniza em [+posterior] com a vogal precedente, mas deixa passar o traço para a vogal do sufixo em Zsúzsi-val. Para Archangeli e Pulleyblank (2007), a opacidade é o efeito esperado, enquanto a transparência é o que é intrigante e precisa ser explicado. Os autores indicam uma série de questões com relação aos segmentos transparentes, por exemplo quais são as suas propriedades melódicas ou prosódicas, qual a distância que pode ser percorrida entre alvo e gatilho e quais os mecanismos formais que tornam possível o efeito de transparência. Isso tudo sugere que os alegados casos de transparência mereçam uma reanálise, para verificar se o efeito de transparência não pode ser derivado de outras propriedades das estruturas envolvidas. No caso da harmonia em português, não parece haver casos sistemáticos de vogais transparentes. Casos como $a b[\mathrm{u}] r r[\mathrm{e}] c i d o$ e $p[\mathrm{u}] d[\mathrm{e}]$ ria não parecem envolver harmonia vocálica (BISOL, 1988), mas esta é uma questão que merece exame nos diversos corpora levantados nos últimos anos.

O foco de Archangeli e Pulleyblank (2007) está nas propriedades que qualquer modelo teórico precisa derivar e não nas propriedades formais da gramática propriamente dita. O texto nos faz ver a harmonia vocálica de forma diferente da perspectiva difundida pela fonologia autossegmental. O processo de harmonia é visto como uma situação geral em que todos os segmentos de um determinado domínio possuem o mesmo valor de um determinado traço. Os efeitos dessa harmonia geral são diminuídos pelas diversas condições limitadoras que atuam sobre ela e o foco acaba recaindo sobre essas condições. Condições sobre alvo e gatilho, restrições de domínio e de direcionalidade e a limitação da iteração são todas propriedades que podem ser investigadas e descritas nos dados de uma língua e que devem ter papel em outros fenômenos, independentemente da harmonia.

\section{CONCLUSÃO}

Analisamos neste artigo a harmonia vocálica da pretônica em português à luz de dois textos que buscam sintetizar as propriedades da harmonia vocálica e que apontam algumas dificuldades que fenômenos dessa natureza levantam para as teorias fonológicas. O texto de Hulst e van der Wijer (1995) parte do pressuposto de que os processos de harmonia vocálica sejam instâncias do processo assimilatório de espraiamento de traços entre segmentos vocálicos. No texto de Archangeli e Pulleyblank (2007), essa posição não fica tão clara. Embora muitas das colocações dos autores evidenciem a influência da perspectiva autossegmental, perspectiva que os

\footnotetext{
${ }^{10}$ Existe uma proposta em Nevins (2010), mas numa perspectiva bastante distinta. Também McCarthy (2009) apresenta uma proposta de limitador da harmonia.

Work. Pap. Linguíst., 13(2): 01-14, Florianópolis, abr/jul, 2013
} 
próprios autores ajudaram a consolidar em diversos trabalhos anteriores, há também visivelmente referência a noções como restrições de marcação, de alinhamento e de fidelidade posicional, entre outras, oriundas da Teoria da Otimalidade. Ao longo desse cotejo entre os dois trabalhos teóricos indicados, buscamos apresentar questões relacionadas com a harmonia vocálica das vogais pretônicas em português. O objetivo foi o de levantar questões que desafiam tanto a discussão teórica quanto a descrição dos dados das diversas variedades do português brasileiro.

\section{REFERÊNCIAS}

ABAURRE, M. B.; SÂNDALO, F. Representação e subespecificação de vogais no português. Cadernos de Pesquisa em Linguística. Porto Alegre, vol. 4, n 1, novembro de 2009. p.21-40.

AMARAL, M. P. Proparoxitonas: teoria e variação. Tese de Doutorado. PUCRS: Porto Alegre, 2000.

ARCHANGELI, D.; PULLEYBLANK, D. Harmony, In: DE LACY, P. (ed.). The Cambridge Handbook of Phonology. Cambridge: Cambridge University Press, 2007. p. 353-378

BECKMAN, J. Positional Faithfulness. In: MCCARTHY, J. J. (ed.). Optimality Theory in Phonology: A. Reader. Oxford/Malden: Blackwell, 2003.

BISOL, L. A harmonização vocálica na fala culta. DELTA: Documentação de estudos em linguística teórica e aplicada. 4(1), 1988.p:1-20.

BISOL, L. Harmonia Vocálica: Uma regra variável. Tese de Doutorado. Faculdade de Letras/UFRJ, Rio de Janeiro, 1981.

BISOL, L. Vowel harmony: a variable rule in Brazilian Portuguese. Language Variation and Change 1(2), 1989. p.:185-198.

CALABRESE, A. Metaphony in Salentino. Rivista di grammatica generativa p.9-10, 1985.

CALLOU, D.; LEITE, Y.; MORAES, J. A elevação das vogais pretônicas no português do Brasil: processo(s) de variação estável. Letras de Hoje, v. 37, n.1, PUCRS, 2002, p. 9-24.

CALLOU, D.; MORAES, J.; LEITE, Y.; MACHADO, L. Caracterização acústica das vogais no português brasileiro: sílabas pretônicas e tônicas. In: HORA, D. da. Vogais no ponto mais oriental das Américas. João Pessoa: Idéia/Editora Universitária UFPB, 2009. p. 133-144.

CARDOSO, S. A. M. As vogais médias pretônicas no brasil: uma visão diatópica. In: AGUILERA, V.A.(org.) Português no brasil. Estudos fonéticos e fonológicos. Londrina: Editora da UEL,1999. p. 93-108

CASSIQUE, O.; CRUZ, R; DIAS, M. P.; OLIVEIRA, D. A. Análise do processo de alteamento das vogais médias pretônicas no português falado em Breves (PA). In: HORA, D. da. Vogais no ponto mais oriental das Américas. João Pessoa: Idéia/Editora Universitária UFPB, 2009.p. 111-132. 
CHAGAS DE SOUZA, P. O finlandês e o húngaro e a tipologia da harmonia e da desarmonia vocálica. Revista Letras. Curitiba, n. 63, p. 119-138, maio/ago. 2004. Editora UFPR

CHO, Y.-M. Y. Parameters of Consonantal Assimilation. PhD dissertation, Stanford University, Stanford, 1990. Publicado em LINCOM Studies in Theoretical Linguistics 15. 266pp. 1999

CLEMENTS, G. N.; HUME, E. The Internal Organization of Speech Sounds. In: GOLDSMITH, J.(ed.) Handbook of Phonological Theory. Cambridge, Massachusetts: Blackwell, 1995

COLLISCHONN, G. Harmonia vocálica da pretônica - um tema e suas variações. Manuscrito. Universidade Federal do Rio Grande do Sul, 2013.

FIKKERT, P. From phonetic categories to phonological features specification: Acquiring the European Portuguese vowel system. Lingue e Linguaggio 4 (2), 2005: p.263-280.

GUY, G. R. Advanced varbrul analysis. In: FERRARA, K.; BROWN, B.; WALTERS, K.; BAUGH, J. (ed.) Linguistic change and contact. Austin, Texas: Department of Linguistics, University of Texas at Austin, 1988 p. 124-36.

HORA, D. da. Uso variável das vogais no português do Brasil. Manuscrito. 2005

HULST, H.G. van der; WEIJER, J. van de. Vowel harmony. In: J.A. Goldsmith (ed.). The Handbook of phonological theory. Basil Blackwell, Oxford, 1995. p. 495-534

LADEFOGED, P.; MADDIESON, I. The sounds of the world's languages. Cambridge, MA: Blackwell, 1996.

LEE, S.-H.; OLIVEIRA, M. A. de. Variação Inter- e Intra-Dialetal no Português Brasileiro: Um Problema para a Teoria Fonológica. In: HORA, D. da; COLLISCHONN, G. (org.). Teoria Linguística: fonologia e outros temas. João Pessoa: Editora Universitária da UFPB, 2003, v., p. 67-91

LEITE, Y.; CALLOU, D.; MORAES, J. Processos de mudança no português do Brasil: variáveis sociais. In: CASTRO, I.; DUARTE, I. Razões e Emoção. Miscelânea de estudos em homenagem a Maria Helena Mira Mateus. Vol. 1. Lisboa, Imprensa Nacional/Casa da Moeda, 2003. P. 87-114. Disponível em $<$ http://www.letras.ufrj.br/posverna/docentes/62341-1.pdf>. Acesso: 10 jan. 2003.

MATZENAUER, C.L.B. Introdução à teoria fonológica. In: BISOL, L. (org.). Introdução a estudos de fonologia do português brasileiro. 4 ed. Porto Alegre: EDIPUCRS, 2005, v. 1, p. 11-81.

MATZENAUER, C.L.B.; MIRANDA, A. R. M. Uma análise da harmonia vocálica e da metafonia nominal com base em restrições. In: HORA, D. da; COLLISCHONN, G. (org.). Teoria Linguística: fonologia e outros temas. João Pessoa: Editora Universitária da UFPB, 2003, v., p. 92-113.

MATZENAUER, C.L.B.; MIRANDA, A. R. M. Traços distintivos e a aquisição das vogais do PB. In: HORA, D. da. Vogais no ponto mais oriental das Américas. João Pessoa: Idéia/Editora Universitária UFPB, 2009.p 45-63. 
MCCARTHY, J. J.; PRINCE, A. Generalized Alignment: Introduction and Theory. In MCCARTHY, J. J. (ed.). Optimality Theory in Phonology: A. Reader. Oxford/Malden: Blackwell, 2003.

MCCARTHY, J. J. Harmony in harmonic serialism. University of Massachusetts, Amherst, 2009. Disponível em: <http://works.bepress.com/john_j_mccarthy/612011>. Acesso: 10 jan. 2003.

NEVINS, A. Review of Jonathan Barnes' Strength and Weakness at the Interface: Positional Neutralization in Phonetics and Phonology. Phonology, v. 24 n. 3, 2007. p. 461-469.

NEVINS, A. Locality in Vowel Harmony. Cambridge, Massachusetts: MIT Press, 2010 PAOLILlO, J. C. Analyzing Linguistic Variation: Statistical Models and Methods. Stanford, California: CSLI Publications, 2002.

RÉVAH, I. S. L. L'Évolution de la pronunciation au Portugal et au Brésil du XVIe siécle à nos jours. Atas do Primeiro Congresso de Língua Falada no Teatro. Rio de Janeiro: MEC, 1958. P. 387-399.,

RODRIGUES, D.; ARAÚJO, M. P. As vogais médias pretônicas /e/ e /o/ no português falado em Cametá/Pará - a harmonização vocálica numa abordagem variacionista. Cadernos de Pesquisa em Linguística, PUCRS/FALE, v. 3, n 1, novembro de 2007. p.104-126.

SCHWINDT, L.C. S. A regra variável de harmonização vocálica no RS. In: BISOL, L; BRESCANCINI, C. Fonologia e variação: recortes do Português brasileiro. Porto Alegre: EDIPUCRs, 2002. P. 161-182

SCHWINDT, L.C. S. O prefixo no português brasileiro: análise prosódica e lexical. DELTA, vol.17, no. 2, São Paulo, 2001.

SCHWINDT, L.C. S. A harmonia vocálica em dialetos do sul do país: uma análise variacionista. Dissertação de mestrado. Porto Alegre: PUCRS, 1995.

SILVA, M. E. da. O alçamento das vogais médias pretônicas na fala de São José do Norte/RS: Harmonia Vocálica. Dissertação de mestrado. Porto Alegre, UFRGS, 2012. Disponível em:

$<$ http://www.lume.ufrgs.br/bitstream/handle/10183/56035/000858616.pdf > . Acesso em: 10 jan, 2003

STERIADE, D. Underspecification and markedness. In: GOLDSMITH, J. (ed.) Handbook of Phonological Theory. Cambridge, Massachusetts: Blackwell, 1995

TAGLIAMONTE, S. A. Analyzing Sociolinguistic Variation. Cambridge: Cambridge University Press, 2006.

TENANI, L; SILVEIRA, A.A.M. O alçamento das vogais médias na variedade culta do noroeste paulista. Alfa, São Paulo, 52 (2). p. 447-464, 2008.

YOUNG, R.; BAYLEY, R.VARBRUL analysis for second language acquisition research. In: BAYLEY, R.; PRESTON, D. (ed.) Second Language Acquisition and Linguistic Variation. Philadelphia: John Benjamins, 1996.

WETZELS, W. L. Mid Vowel Neutralization in Brazilian Portuguese. Cadernos de Estudos Lingüísticos. Campinas: UNICAMP/IEL, v.23, 1992, p. 19-55.

Recebido: $16 / 06 / 2013$

Aceito: $30 / 08 / 2013$ 